\title{
Training program conference of "Good Pain Management Ward" was launched in Wuhan
}

Author/Photo: Yi Cheng, from Tongji Cancer Center, Tongji Hospital, Tongji Medical College, Huazhong University of Science and Technology, Wuhan 430030, China

Received: 13 March 2012 / Revised: 20 March 2012 / Accepted: 25 March 2012

(c) Huazhong University of Science and Technology and Springer-Verlag Berlin Heidelberg 2012

On March 6th, the training program conference of "Good Pain Management Ward" (GPM ward) was launched in the conference hall of Westin Hotel, Wuhan. The conference was hosted by Clinics Medical Secretary, Ministry of Health, and undertaken by CSCO and Mundipharma (China) Pharmaceutical Co., Ltd. Three hundreds experts, doctors and nurses, from departments of oncology, pain, anesthesiology and pharmacy, in 6 provinces (including Hubei, Hunan, Jiangxi, Shanxi, Shanxi, Henan), attended the conference.

The conference was hosted by Professor Shiying Yu, the chief of Tongji Cancer Center, Tongji Hospital. Minggang Zhao, the deputy director of Clinics Medical Secretary, Ministry of Health, emphasized the meaning of GPM ward. He pointed out that, the inherent spirit was consistent with that of "three good one satisfactory" program now carried out all over the country. Alleviating cancer pain was the important responsibility for medical staff, since it could improve the patients' quality life
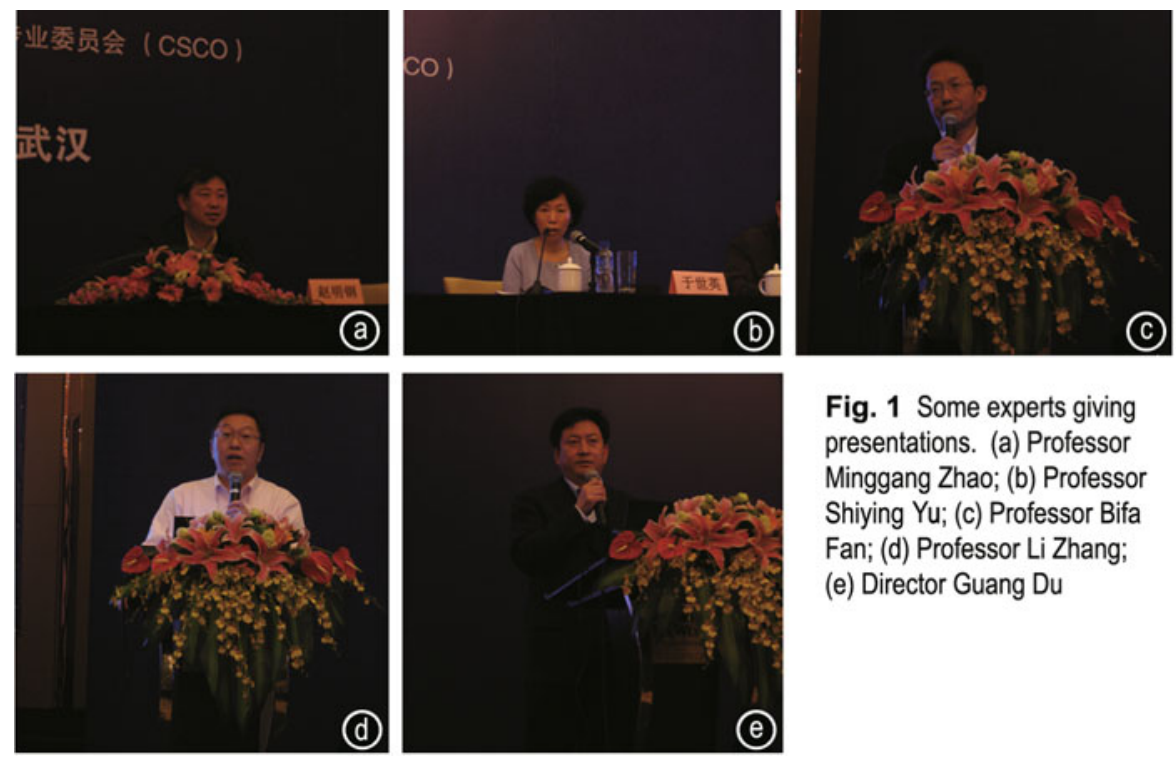

and strengthen the curative effect. He wished the medical staff could also improve their clinical practice through the training program.

Professor Shiying Yu introduced the training program. She pointed out that the status quo of cancer pain treatment still need to be improved, due to a series of reasons: the lack of knowledge, the conservative attitude, the strict governess of opioid drugs and some historical reason. The Ministry of Health launched GPM ward last year, and from January 2012, the training program kicked off. The first program was held in Shanghai, followed by Wuhan. Experts from 6 provinces came together at the conference. She hoped that the level of cancer pain treatment could be elevated after the training program.

The conference was consisted of 4 speeches. Professor Bifa Fan from China-Japan Friendship Hospital, gave a speech on "the mechanism of pain and multiple mode alleviating pain". In the speech, he introduced the physiopathological mechanisms of pain and the pharmacology of drugs. Professor Shiying Yu gave a speech on "the criterion of Good Pain Management". In the speech, she explained the criteria about the assessment, titration and adverse effects. Professor Li Zhang, from Sun YatSen University Cancer Center, gave a speech on "how to grade GPM ward". In the speech he explained the details of judging

Fig. 1 Some experts giving presentations. (a) Professor Minggang Zhao; (b) Professor Shiying Yu; (c) Professor Bifa Fan; (d) Professor Li Zhang; (e) Director Guang Du criteria of GPM ward. Director Guang $\mathrm{Du}$, from Pharmacy of Wuhan Tongji Hospital, gave a speech on "the standardize management of narcotic and psychoactive drugs". In the speech he gave the details of laws and guidelines of management of narcotic and psychoactive drugs. 